\title{
Bone mineral density and body composition in adult patients with cystic fibrosis
}

\author{
A B Grey, R W Ames, R D Matthews, I R Reid
}

\begin{abstract}
Background-Cystic fibrosis is a multisystem disease characterised by chronic pulmonary sepsis and malnutrition. To ascertain whether osteoporosis is a feature of cystic fibrosis in adult patients, total body and regional bone mineral density (BMD) was measured in a group of eight men and eight women aged 17-42 years.

Methods-Total body and regional BMD (lumbar spine L2-L4, femoral neck, trochanteric, and Ward's triangle), as well as total body fat and lean mass, were measured by dual energy $x$ ray absorptiometry. A range of biochemical, lifestyle, and anthropometric variables was also assessed.

Results-Patients with cystic fibrosis had significantly reduced bone density at all sites compared with normal young adults. The mean reductions ranged from $7 \%$ at Ward's triangle to $13 \%$ at the trochanter. Body mass index (BMI) was positively correlated with BMD at four sites and disease severity negatively correlated with BMD at two sites. Other biochemical and anthropometric variables were not predictive of bone density. Total body fat mass was reduced by $\mathbf{3 0} \%$ compared with normal young adults.

Conclusions-Bone density is decreased in adult patients with cystic fibrosis and BMI and disease severity are independent predictors of bone density.
\end{abstract}

(Thorax 1993;48:589-593)

Department of Medicine, University of Auckland A B Grey $R$ W Ames I R Reid

\section{Department of}

Radiology, Auckland Children's Hospital R D Matthews

Reprint requests to: Dr A B Grey, Department of Endocrinology, Auckland Hospital, Park Rd Hospital, Park Rd,

Received 30 July 1992 Returned to authors 10 November 1992 Revised version received 14 December 1992 Accepted 21 December 1992 6-18 years. ${ }^{1}$ Distal forearm bone mineral content was normal in six patients under the age of 10 years but the same authors found that $60 \%$ of subjects over the age of 15 years exhibited reduced bone mineral content at the same site. ${ }^{2}$ In this group of adolescents the reduction in bone mass correlated with the degree of observed weight reduction. The only published study on bone mass in adult patients with cystic fibrosis reported a $14 \%$ reduction in distal forearm bone mineral content in 21 subjects of average age 21 years. ${ }^{3}$

More recently Gibbens et al used quantitative computed tomography to compare the lumbar spinal BMD of a predominantly paediatric population of patients with cystic fibrosis (average age 12 years) with that of age matched, normal controls. ${ }^{4}$ In addition to a $10 \%$ reduction in spinal $\mathrm{BMD}$, they found that disease severity as measured by the Schwachman scoring system and poor nutritional state as assessed by anthropometric measurements (skin thickness, forearm circumference) correlated with BMD.

Improvements in the standard of care of patients with cystic fibrosis have resulted in a progressively increasing life expectancy and median survival is now well into the third decade. ${ }^{5}$ It is likely that this trend will continue. If the osteopenia found in children with cystic fibrosis is confirmed in the adult population, morbidity from osteoporotic fractures is a potential consequence. The present study was therefore carried out to determine whether osteopenia occurs in adults with cystic fibrosis, and to delineate clinical and biochemical predictors of BMD.

\section{Methods}

PATIENTS

Of the 22 patients attending the adult cystic fibrosis clinic at Auckland Hospital, 16 (eight men, eight women) agreed to participate in the study. All were white and were aged 17-42 years. Cystic fibrosis had been diagnosed in each subject by the presence of abnormally increased electrolyte levels in sweat by pilocarpine iontophoresis. Pulmonary colonisation by Pseudomonas aeruginosa was present in 15 subjects. Mean forced expiratory volume in one second was $65 \%$ of predicted (range $35-100 \%$ ). None of the subjects had a major systemic disease other than cystic fibrosis. None was taking corticosteroids, thiazide diuretics, anticonvulsants, or calcium preparations at the time of entry into the study. None of the men was taking sex hormones but two of the women were taking oestrogen containing contracep- 
tive pills. Two men and two women were taking calciferol in doses ranging from 1 to $40 \mu \mathrm{g}$ per day. One man was taking $1 \mu \mathrm{g}$ $1 \alpha$-hydroxyvitamin D (a-hydroxycalciferol) daily.

\section{CONTROLS}

Body composition and BMD data in the patients were compared with those of 65 normal young adults (42 men, 23 women) of similar age and height. It has recently been shown that the BMD of postpubertal adolescents is within the normal young adult range. ${ }^{6}$

\section{BONE DENSITY MEASUREMENTS}

Total body BMD and BMD at the lumbar spine (L2-L4), femoral neck, Ward's triangle, and trochanter, as well as total body fat and lean mass, were measured by dual energy $x$ ray absorptiometry with a Lunar DPX scanner (Lunar, Madison, Wisconsin). This technique has previously been described ${ }^{7}$ and measures BMD, fat mass, and lean mass from the relative attenuation of two energies of $x$ rays which are absorbed differently by the various tissues. The precision (coefficient of variances) of these measurements in our laboratory is $0.4 \%$ for total body $\mathrm{BMD}, 1.0 \%$ for lumbar spinal BMD, $1.4 \%$ for femoral neck BMD, $2 \cdot 7 \%$ for fat mass, and $\mathbf{0 \cdot 8 \%}$ for lean mass. All scans were performed and analysed by one operator (RA).

\section{CLINICAL ASSESSMENT}

\section{Disease severity}

The NIH prognostic scoring system, ${ }^{8}$ based on respiratory, nutritional, activity, and attitudinal aspects of the disease, was applied by the same investigator (AG) to each subject. Compared with earlier assessment procedures, this system places increased emphasis on the pulmonary aspects of the disease. The score has a maximum of 100 (75 for pulmonary factors and 25 for nutritional and general factors) with a higher score indicating more severe disease. All the radiological scoring was carried out by one radiologist ( $R M)$.

\section{Physical activity}

A validated seven day physical activity recall questionnaire was administered to each subject. ${ }^{9}$ This provided an assessment of the amount of time spent in all physical activities.
The energy expenditure used in each type of activity had previously been determined, ${ }^{9}$ and total energy expenditure could thus be calculated from the sum of the products of the time spent in each activity and its metabolic cost.

\section{Calcium intake}

Calcium intake was assessed by a previously described dietary recall questionnaire, modified for local requirements. ${ }^{10}$

\section{Physical examination}

Tanner pubertal staging was performed. ${ }^{11}$ Clinical evidence of osteomalacia and chronic liver disease was sought and a respiratory examination performed. Body mass index $\left(\mathrm{BMI}=\right.$ weight $/$ height $\left.^{2}\right)$ was calculated .

\section{Radiology}

Anteroposterior and lateral chest radiographs were taken for each subject at the same time as the densitometry was performed. The lateral films were examined for evidence of thoracic vertebral wedging. Anterior and posterior vertebral heights were measured and the difference expressed as a percentage of the latter.

\section{BIOCHEMICAL DATA}

All specimens were collected after an overnight fast.

\section{Serum}

The levels of calcium, phosphate, alkaline phosphatase, albumin, and liver enzymes in the serum were measured by an Hitachi 737 autoanalyser. Intact parathyroid hormone levels were measured by two site immunoradiometric assay (Nichols Institute, San Juan Capistrano, California); 25-hydroxyvitamin $\mathrm{D}$ and 1,25 -dihydroxyvitamin $\mathrm{D}$ by competitive protein binding assay (Nichols Institute, San Juan Capistrano, California); insulin-like growth factor 1 (IGF-1) by an acid ethanol cryoprecipitate method; vitamins $\mathrm{A}$ and $\mathrm{E}$ by hexane extraction high pressure liquid chromatography; oestradiol by radioimmunoassay; and testosterone by a commercially supplied direct radioimmunoassay (Coat-ACount, Diagnostic Products, Los Angeles, California). The coefficients of variation for the hormone assays were $8 \%$ for parathyroid hormone, $11 \%$ for 25 -hydroxyvitamin $\mathrm{D}$ and

Table 1 Mean (SD) population characteristics of study groups

\begin{tabular}{|c|c|c|c|c|c|c|}
\hline & \multicolumn{3}{|l|}{ Patients } & \multicolumn{3}{|l|}{ Controls } \\
\hline & $\begin{array}{l}\text { Men } \\
(n=8)\end{array}$ & $\begin{array}{l}\text { Women } \\
(n=8)\end{array}$ & $\begin{array}{l}\text { Total } \\
(n=16)\end{array}$ & $\begin{array}{l}\text { Men } \\
(n=42)\end{array}$ & $\begin{array}{l}\text { Women } \\
(n=23)\end{array}$ & $\begin{array}{l}\text { Total } \\
(n=65)\end{array}$ \\
\hline Age (years) & $26(8)$ & $21(7)$ & $23(8)$ & $27(7)$ & $24(4)$ & $26(6)$ \\
\hline Weight (kg) & $60(9)^{\star \star}$ & $56(8)^{\star}$ & $58(8)^{\star \star}$ & $78(9)$ & $62(7)$ & $72(12)$ \\
\hline Height (m) & $1.75(0.06)$ & $1.64(0.08)$ & $1.69(0.09)$ & $1.76(0.07)$ & $1.66(0.06)$ & $1.72(0.07)$ \\
\hline $\mathrm{BMI}\left(\mathrm{kg} / \mathrm{m}^{2}\right)$ & $20(2)^{\star \star}$ & $21(1)^{\star}$ & $20(2)^{\star \star}$ & $25(3)$ & $24(4)$ & $25(4)$ \\
\hline Disease severity $(\max 100)$ & $43(17)$ & $25(11)$ & $34(17)$ & & & \\
\hline Calcium intake (mg/day) & $650(305)$ & $600(373)$ & $625(330)$ & & & \\
\hline Energy expenditure (kcal/kg/day) & $38(7)$ & $39(4)$ & $39(6)$ & & & \\
\hline
\end{tabular}

${ }^{\star} \mathrm{p}<0.05 v$ controls; ${ }^{\star \star} \mathrm{p}<0.001 v$ controls.

BMI-body mass index. 
1,25-dihydroxyvitamin $\mathrm{D}, 9 \%$ for IGF-1, $10 \%$ for vitamins $\mathrm{A}$ and $\mathrm{E}, 10 \%$ for testosterone, and $15 \%$ for oestradiol.

\section{Urine}

Hydroxyproline levels were measured in two hour second-voided samples of urine in 10 subjects and expressed as a ratio to creatinine. Twenty four hour urinary calcium excretion was measured in 12 subjects on an unrestricted diet.

\section{STATISTICAL ANALYSIS}

Total body BMD and BMD values at each individual site were expressed as a percentage of the mean normal value and the difference of the patients' values from 100 assessed by the Student's $t$ test. This process was repeated after adjustment for body weight. Relationships between variables were assessed with Pearson correlation coefficients. Multiple regression analysis was performed, with $\mathbf{B M D}$ as the dependent variable, when significant correlations were found between more than one variable and BMD at any site.

The study was approved by the Auckland Area Health Board Ethics Committee. Written informed consent was obtained from each subject.

\section{Results}

Table 1 records the population characteristics of the subjects with cystic fibrosis and controls. The men with cystic fibrosis were, on average, 5 years older than the women, which may explain the greater disease severity in this group ( $p=0.02$ men $v$ women). The patients with cystic fibrosis were relatively lean, as evidenced by a mean BMI of $20 \mathrm{~kg} / \mathrm{m}^{2}$, and significantly lighter than the controls. Mean dietary calcium intake was modest at 625 $\mathrm{mg} /$ day.

All subjects were Tanner pubertal stage 5 . One man and four women had sex hormone levels below the lower limit of the normal range. Two women were oligomenorrhoeic, one of whom had a subnormal oestradiol level. One man and one woman had clinical evidence of hepatic cirrhosis and portal hypertension. Both had longstanding abnormalities of liver function tests and ultrasonographic evidence of hepatic fibrosis, splenomegaly, and oesophageal varices. None of the subjects had suffered fractures, either spontaneously or as a result of minor trauma. None had symptoms or clinical evidence of osteomalacia.

Figure 1 illustrates total body BMD and $B M D$ values at each site expressed as a percentage of mean normal young adult values. At each site the mean BMD of the subjects with cystic fibrosis was significantly lower than the corresponding mean of young normals. Mean reduction in total body BMD of the patients with cystic fibrosis was $10.5 \%$ $(\mathrm{p}<0.001)$. At the individual sites assessed, BMD in the study group was reduced by $12.5 \%$ at the lumbar spine $(p<0.001)$, by $11: 1 \%$ at the femoral neck $(p<0.001)$, by $13 \%$ at the trochanter $(p<0.001)$, and by $7 \%$ at Ward's triangle $(p=0.02)$. The reductions in femoral neck and trochanteric BMD values were significantly greater in male than female subjects with cystic fibrosis $(p<0.01$ for both sites).

Figure 2 shows total body fat and lean mass expressed as a percentage of normal young adult values. Fat mass was reduced by $30 \%$ in the group as a whole $(p<0.001)$, with the difference being greater in the men (mean reduction $41 \%$ ) than in the women (mean reduction 19\%). Lean mass was also

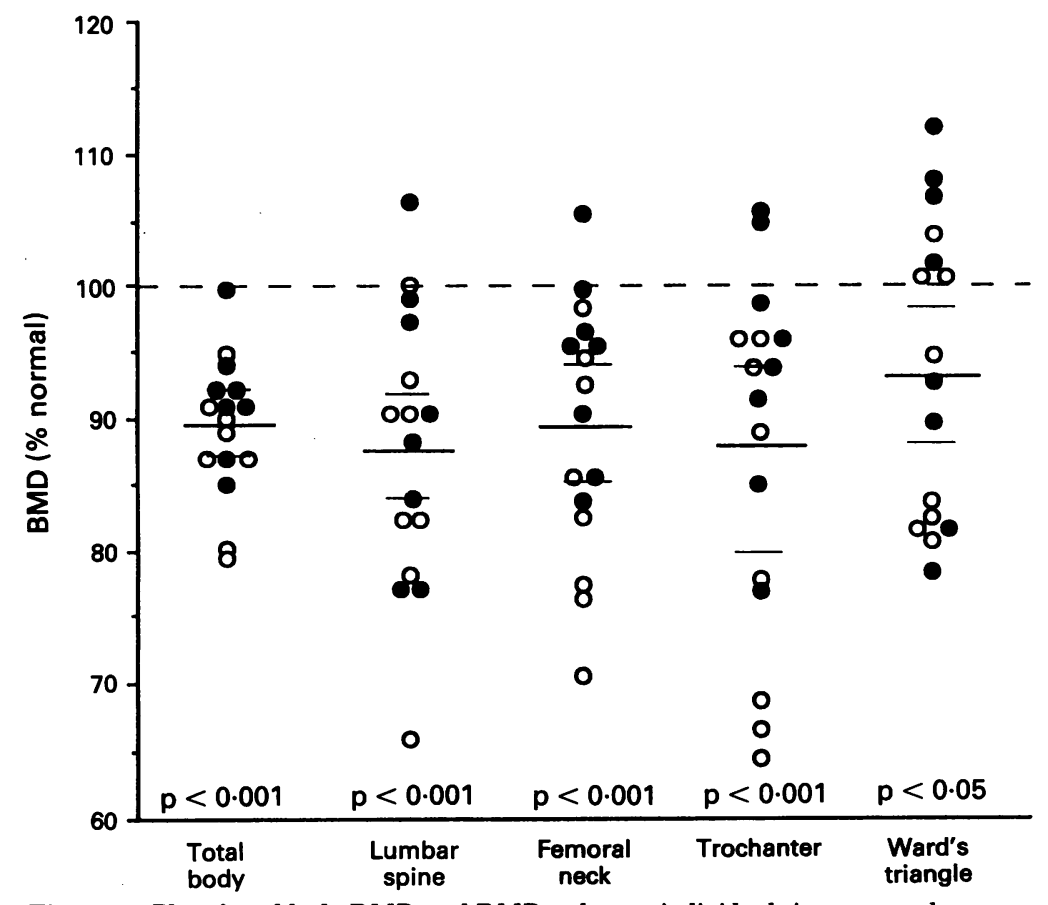

Figure 1 Plot of total body BMD and BMD values at individual sites expressed as a percentage of the normal young adult mean values for male (O) and female (O)patients with cystic fibrosis. Mean (SD) values are shown by the solid horizontal lines.

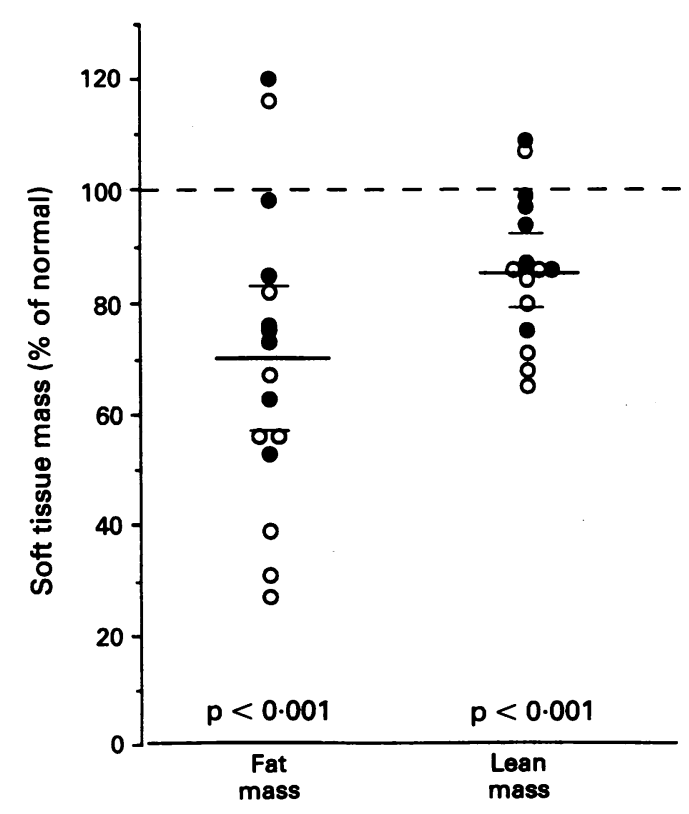

Figure 2 Fat and lean body mass of male (O) and female (O)patients with cystic fibrosis expressed as a percentage of normal young adult mean values. Mean (SD) values are indicated by the solid horizontal lines. 
Table 2 Mean (SD) calcium and calcium related biochemical results in patients with cystic fibrosis

\begin{tabular}{lcc}
\hline & $\begin{array}{l}\text { Patients with } \\
\text { cystic fibrosis }\end{array}$ & Normal range \\
\hline Serum & & \\
$\quad$ Total calcium $(\mathrm{mmol} / \mathrm{l})$ & $2 \cdot 33(0 \cdot 07)$ & $2 \cdot 10-2 \cdot 55$ \\
Ionised calcium $(\mathrm{mmol} / \mathrm{l})$ & $1 \cdot 24(0 \cdot 03)$ & $1 \cdot 17-1 \cdot 28$ \\
Parathyroid hormone $(\mathrm{pmol} / \mathrm{l})$ & $2 \cdot 5(1 \cdot 1)$ & $1-5$ \\
25-hydroxyvitamin D $(\mu \mathrm{g} / \mathrm{l})$ & $18 \cdot 0(7 \cdot 4)$ & $14-76$ \\
1,25-dihydroxyvitamin D (ng/l) & $43 \cdot 3(12)$ & $18-62$ \\
Urine & $3 \cdot 66(2 \cdot 2)$ & $2 \cdot 5-7 \cdot 5$ \\
24 hour calcium (mmol/day) & $36(19)$ & $<30$ \\
Hydroxyproline/creatinine $(\mu \mathrm{mol} / \mathrm{mmol})$ & & \\
\hline
\end{tabular}

Figure 3 Total body $B M D$ of patients with cystic fibrosis expressed as a percentage of the normal young adult mean value plotted against body mass index (BMI).

lower in the patients with cystic fibrosis than in normal subjects (mean reduction $14 \%$, $\mathrm{p}<0.001$ ).

Table 2 details results of calcium and calcitropic hormone measurements performed in the patients with cystic fibrosis. Five had levels of 25-hydroxyvitamin $D$ below the normal adult range; none had serum calcium or parathyroid hormone levels outside the normal range. Urinary hydroxyproline excretion (range $36-60 \mu \mathrm{mol} / \mathrm{mmol}$ creatinine) was raised in $50 \%$ of the patients. Vitamin $A$ and $E$ levels were normal in 15 of the 16 subjects with cystic fibrosis.

Correlation coefficients were calculated between percentage normal BMD at each site and a number of lifestyle, anthropometric, and biochemical variables. BMI correlated positively with total body BMD $(r=0.64$, $\mathrm{p}<0.02$; fig 3) and with BMD at the three femoral sites (femoral neck $r=0.56$, $\mathrm{p}<0.05$; trochanter $r=0.64, \mathrm{p}<0.02$; and Ward's triangle $r=0.51, \mathrm{p}<0.05)$. Disease

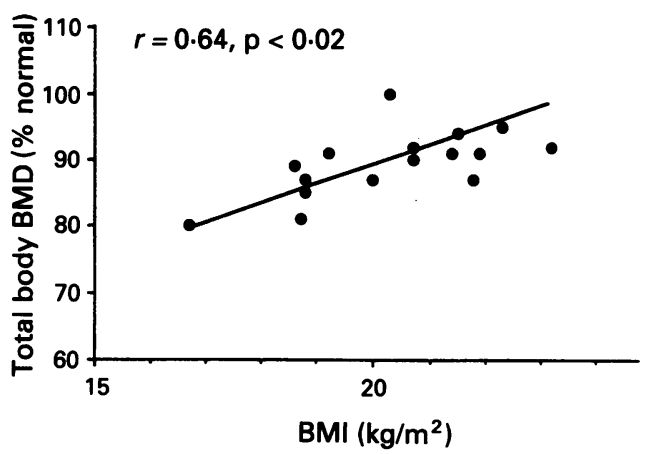

Figure 4 Femoral neck $B M D$ of patients with cystic fibrosis expressed as a percentage of the normal young adult mean value plotted against disease severity. severity correlated inversely with BMD at the femoral neck $(r=-0.52, \mathrm{p}<0.05$; fig 4) and trochanter $(r=-0.57, \mathrm{p}<0.05)$. Multiple regression analyses were performed with BMI and disease severity as the independent variables, and either trochanteric or femoral neck $\mathrm{BMD}$ as the dependent variable. At each site the regression was significant $(p<0.01$ and $p<0.05$ for trochanter and femoral neck, respectively) and the two independent variables had a similar influence on BMD.

Other postulated influences on BMD such as dietary calcium intake and physical activity were not correlated with BMD. Adjustment of BMD for body weight resulted in serum albumin being significantly correlated with $\mathrm{BMD}$ at the lumbar spine $(r=0.54$, $\mathrm{p}<0.05)$ and Ward's triangle $(r=0.52$, $\mathrm{p}<0.05)$, but did not reveal any other significant associations.

Review of lateral chest radiographs of the subjects with cystic fibrosis revealed that $31 \%$ (five of 16) exhibited greater than $20 \%$ wedging of at least one thoracic vertebra. Four of these five subjects had a spinal BMD value more than one standard deviation below the mean for normal young adults.

\section{Discussion}

This study has shown that adult patients with cystic fibrosis have reduced bone density at all the sites assessed, $69 \%$ and $44 \%$ of the subjects having reductions of greater than one standard deviation in spinal and femoral neck $B M D$, respectively. Individual site reduction of BMD of one standard deviation confers a relative risk of fracture of $2 \cdot 2$ at the lumbar spine, ${ }^{12}$ and an estimated $30 \%$ lifetime risk of femoral neck fracture. ${ }^{13}$ Reduction of spinal and femoral neck BMD of greater than two standard deviations was seen in $38 \%$ and $19 \%$ of the patients respectively, placing these individuals at substantially greater risk of fracture.

BMI correlated positively, and disease severity correlated negatively, with BMD. The positive relationship with $\mathrm{BMI}$ is consistent with the findings of Gibbens et al who reported that skinfold thickness and forearm circumference were predictive of spinal BMD in children with cystic fibrosis. ${ }^{4}$ Body weight has previously been shown to be closely related to BMD in normal men ${ }^{14}$ and women. ${ }^{15}$ The negative effect of disease severity may in part be mediated by its effects on body weight, as chronic severe pulmonary and pancreatic disease leads to greater degrees of malnutrition. Multiple regression analysis, however, suggested that disease severity and BMI had independent influences on BMD. It is possible that cytokines produced in response to persisting sepsis may account for the influence of disease severity. Levels of tumour necrosis factor $a$, which increases bone resorption, ${ }^{16}$ are persistently raised in patients with cystic fibrosis, perhaps generated in response to pulmonary colonisation by Pseudomonas aeruginosa. ${ }^{17}$

Several other potential mechanisms for the 
osteopenia in these patients were not supported by the correlation analyses reported herein. Delayed attainment of adult levels of sex hormones has been reported in cystic fibrosis, ${ }^{18}$ and sex hormone deficiency is known to be associated with reduced trabecular and cortical bone mass in both young women $^{19}$ and young men. ${ }^{20}$ We found no relationship between sex hormone levels and BMD in the patients with cystic fibrosis. The reduction in spinal $B M D$ in children with cystic fibrosis also suggests that factors other than sex hormones are important. ${ }^{4}$ We found lowered 25-hydroxyvitamin $\mathrm{D}$ levels in these patients, as have others, ${ }^{13}$ but there was no correlation between levels of this vitamin D metabolite and BMD. Serum calcium levels have been noted to be lower, and immunoreactive parathyroid hormone levels higher, in patients with cystic fibrosis than in normal subjects, ${ }^{3}$ leading to speculation that such abnormalities may contribute to the reduced bone mass of patients with cystic fibrosis. These indices were, however, normal in our subjects.

The clinical significance of these findings remains to be determined. Osteopenia and the resulting vertebral deformities are likely to contribute to the back pain which has been reported in $94 \%$ of patients with cystic fibrosis and which interferes with their work, exercise, coughing, and chest physiotherapy. ${ }^{21}$ Limitations of physiotherapy techniques are known potentially to compromise respiratory function. ${ }^{22}$ Osteoporosis is also a common complication of organ transplantation ${ }^{23-26}$ and pre-existing bone disease may render patients with cystic fibrosis undergoing lung transplantation at a significantly higher risk of fractures.

At present therapeutic modalities for young adults with osteoporosis are limited, but new agents, particularly the expanding bisphosphonate class of drugs, show promise in its treatment. ${ }^{27}$ As more patients with cystic fibrosis live into the third decade and beyond, with or without organ transplantation, the assessment and treatment of osteoporosis may need to become an integral part of the management of this multisystem disease.

1 Solomons NW, Wagonfeld JB, Rieger C, Jacob RA, Bolt $M$, Van der Horst J, et al. Some biochemical indices of nutrition in treated cystic fibrosis patients. Am $\mathcal{F}$ Clin Nutr 1981;34:462-74.

2 Mischler EH, Chesney PJ, Chesney RW, Mazess RB. Demineralization in cystic fibrosis. Am $\mathcal{f}$ Dis Child 1979;133:632-5.

3 Hahn TJ, Squires AE, Halstead LR, Strominger DB. Reduced serum 25-hydroxyvitamin $D$ concentration and disordered mineral metabolism in patients with cys- tic fibrosis. $\mathcal{F}$ Pediatr 1979;94:38-42.

4 Gibbens DT, Gilsanz V, Ines Boechat M, Dufer D Carlson ME, Wang C-I. Osteoporosis in cystic fibrosis. f Pediatr 1988;113:295-300.

5 Huang NN, Schidlow DV, Szatrowski TH, Palmer J, Laraya-Cuasay LR, Yeung W, et al. Clinical features, survival rate, and prognostic factors in young adults with cystic fibrosis. $\mathrm{Am} \mathcal{F}$ Med 1987;82:871-9.

6 Bonjour J-P, Theintz G, Buchs B, Slosman D, Rizzoli R. Critical years and stages of puberty for spinal and femoral bone mass accumulation during adolescence. $\mathcal{f}$ Clin Endocrinol Metab 1991;73:555-63.

7 Mazess RB, Barden JP, Bisek JP, Hanson J. Dual-energy $x$-ray absorptiometry for total-body and regional bonemineral and soft-tissue composition. Am 7 Clin Nutr 1990;51:1106-12.

8 Taussig LM, Kattwinkel J, Friedewald WT, di Sant'Agnese PA. A new prognostic score and clinical evaluation system for cystic fibrosis. $\mathcal{f}$ Pediatr 1973;82:380-90.

9 Wilson PWF, Paffenbarger Jr RS, Morris JN, Havlik RJ Assessment methods for physical activity and physical fitness in population studies: report of a NHLBI workshop. Am Heart ₹ 1986;111:1177-92.

10 Angus RM, Sambrook PN, Pocock NA, Eisman JA. A simple method of assessing calcium intake in Caucasian women. F Am Diet Assoc 1989;89:209-14.

11 Tanner JM. Growth at adolescence. 2nd ed. Oxford: Blackwell, 1962.

12 Ross PD, Davis JW, Epstein RS, Wasnich RD. Pre-existing fractures and bone mass predict vertebral fracture incidence in women. Ann Intern Med 1991;114:919-23.

13 Melton III LJ, Kan SH, Wahner HW, Riggs BL. Lifetime fracture risk: an approach to hip fracture risk assessment based on bone mineral density and age. $\mathcal{F}$ Clin Epidemiol 1988;41:985-94

14 Mazess RB, Barden HS, Drinka PJ, Bauwens SF, Orwoll ES, Bell NH. Influence of age and body weight on spine and femur bone mineral density in US white men. $f$ Bone Miner Res 1990;5:645-52.

15 Mazess RB, Barden HS. Bone density in premenopausal women: effects of age, dietary intake, physical activity, smoking and birth-control pills. Am $\mathcal{f}$ Clin Nutr 1991;53:132-42.

16 Smith DD, Gowen M, Mundy GR. Effects of interferongamma and other cytokines on collagen synthesis in fetal rat bone cultures. Endocrinology 1987;120:2494-9.

17 Norman D, Elborn JS, Cordon SM, Rayner RJ, Wiseman MS, Hiller EJ, et al. Plasma tumour necrosis factor alpha in cystic fibrosis. Thorax 1991;46:91-5.

18 Landon C, Rosenfeld RG. Short stature and pubertal delay in male adolescents with cystic fibrosis. Am $\mathcal{F} D$ is Child 1984;138:388-91.

19 Cann CE, Martin MC, Genant HK, Jaffe RB. Decreased spinal mineral content in amenorrhoeic women. $\mathfrak{f} A M A$ 1984;251:626-9.

20 Foresta C, Ruzza G, Mioni R, Meneghello A, Baccichetti C. Testosterone and bone loss in Klinefelter syndrome. Horm Metab Res 1983;15:56-7.

21 Rose J, Gamble J, Schultz A, Lewiston N. Back pain and spinal deformity in cystic fibrosis. $A m \mathcal{F}$ Dis Child 1987;141:1313-6.

22 Desmond KJ, Schwenk WF, Eli Thomas PT, Beaudry $\mathrm{PH}$, Coates AL. Immediate and long-term effects of chest physiotherapy in patients with cystic fibrosis. $\mathcal{f}$ Pediatr 1983;103:538-42.

23 Julian BA, Laskow DA, Dubovsky J, Dubovsky EV, Curtis JJ, Quarles LD. Rapid loss of vertebral mineral density after renal transplantation. $N$ Engl $\mathcal{f}$ Med 1991; 325:544-50.

24 Porayko MK, Wiesner RH, Hay JE, Krom RAF, Dickson $\mathrm{ER}$, Beaver $\mathrm{S}$, et al. Bone disease in liver transplant recipients: incidence, timing and risk factors. Transplant Proc 1991;23:1462-5.

25 Muchmore JS, Cooper DKC, Ye Y, Schlegel VT, Zudhi $\mathrm{N}$. Loss of vertebral bone density in heart transplant patients. Transplant Proc 1991;23:1184-5.

26 Kelly PJ, Atkinson K, Ward RL, Sambrook PN, Biggs JC, Eisman JA. Reduced bone mineral density in men and women with allogeneic bone marrow transplantation. Transplantation 1990;50:881-3.

27 Fitton A, McTavish D. Pamidronate: a review of its pharmacological properties and therapeutic efficacy in resorptive bone disease. Drugs 1991;41:289-318. 